\title{
Stakeholders in higher education quality assurance: Richness in diversity?
}

\author{
Maarja Beerkens \\ Institute of Public Administration, Leiden University \\ m.beerkens@fgga.leidenuniv.nl \\ Maiki Udam \\ EKKA-Estonian Quality Agency for Higher and Vocational Education \\ maiki.udam@archimedes.ee
}

\begin{abstract}
Stakeholder engagement has become a norm in higher education governance in Europe, particularly in the area of quality assurance. Diverse expectations and experiences of various stakeholder groups are expected to contribute to a more effective and comprehensive quality assurance system. This paper examines empirically the assumption that stakeholders differ in their expectations. Twelve focus group interviews with main stakeholders (university rectors, employers, academic staff, government officials, students) in Estonia demonstrate that the groups indeed have somewhat different perspectives on quality assurance, according to a predictable pattern. We link the results to a theoretical discussion on stakeholder engagement, concluding that the diversity in expectations may enrich the system but it may also force the quality agency to clarify the limits of a public quality assurance system. Furthermore, an engagement process itself may help align the diverse expectations.
\end{abstract}

Keywords: quality assurance, governance, stakeholders, engagement, consultation, collaborative governance 


\section{Introduction}

'Stakeholder engagement' has become a highly visible issue in higher education governance. Stakeholders are invited to advise on national policies and supranational initiatives (OECD, 2002), they are expected to serve in university boards and other advisory bodies (Stensaker \& Vabø, 2013), and their input is recommended for curriculum development and quality evaluation (Diamond, 2008). Academic interest in the topic has increased over the past years as well. A number of recent articles study issues like stakeholder identification, stakeholder management, and stakeholders' expectations to higher education (see Alves, Mainardes, and Raposo (2010)).

This paper focuses on the role of stakeholders in shaping a quality assurance system. According to Hopbach (2014), the diversity of expectations is currently one of the key challenges that European quality assurance agencies face. A lack of agreement about the objectives of quality assurance can inhibit effective implementation of the system (Santiago, Tremblay, Basri, \& Arnal, 2008) as well as reduce its societal legitimacy (Beerkens, 2015b). The 'better regulation' agenda (European Commission 2015), on the other hand, calls for more stakeholder engagement in order to achieve effective regulation and to build a common understanding among stakeholders. The guiding document for quality assurance in Europe, the Standards and Guidelines for Quality Assurance in the European Higher Education Area - ESG (2015) ${ }^{1}$ emphasizes the role of stakeholders throughout the text, and the document itself was a product of active consultation of stakeholders. Stakeholders' needs and expectations have thus taken a prominent place in quality assurance. Quality assurance agencies seem to be well aware of this development and they explore how they can better serve the needs of different stakeholder groups. A recent study by the European Association for Quality Assurance (ENQA) explores how stakeholders use quality information, and the report concludes that current practices may have only limited relevance for major stakeholder groups (Bach et al., 2014).

Furthermore, there are concerns that the ultimate purpose of the quality assurance process remains often ambiguous, as for instance pointed out by a review team of the Irish quality assurance (QQI, 2014). The report called for clarifying the purpose of the exercise and designing the process accordingly. Quality agencies themselves seem to struggle with the question of what exactly the purpose of the system nowadays is, as expectations to quality assurance are shifting and diversifying (Hopbach, 2014).

Could stakeholder engagement address some of these problems, or would such an engagement exacerbate the problems by exposing the system to even more diverse demands? This paper explores a potential effect of stakeholder engagement both conceptually and empirically. We will first examine theoretical arguments for stakeholder involvement, based on the framework of 'collaborative governance'. Thereafter we examine empirically whether expectations to quality assurance indeed vary considerably among different stakeholder

\footnotetext{
${ }^{1}$ http://www.enqa.eu/wp-content/uploads/2015/11/ESG_2015.pdf. Accessed on 26 February 2016.
} 
groups. A diversity of views is namely the key reason to promote stakeholder engagement. Focus group interviews with six types of stakeholders in Estonia will offer evidence about the extent and nature of the diversity. We discuss the implications of the diversity for shaping a quality assurance system in the concluding section. In the next two sections we will introduce the issue of 'stakeholder engagement' as presented in higher education literature, and in governance studies more generally.

\section{Stakeholders in higher education}

There are somewhat different views on who should be considered as 'stakeholders' in higher education, depending on how strictly or broadly we define the concept. By a classic definition, a stakeholder is 'any group or individual who can affect or is affected by the achievement of the organization's objectives' (Freeman, 1984, p. 46). The definition has inspired a long list of potential stakeholders (Burrows, 1999), often categorized as internal (e.g. university leaders, employees, potentially also students) and external stakeholders (e.g. employers, various societal actors, media). David Watson (2012), on the other hand, makes a sobering point that some of the groups have in reality quite a low 'risk' associated with their 'stake', to be really a 'stakeholder'. Nevertheless, universities as large-scale corporations must be able to balance all these societal voices (Watson, 2012).

In the last two decades, two stakeholder groups in particular have gained a widely accepted role in various higher education affairs - students and employers (Smeby \& Stensaker, 1999). The rise of these groups, however, can be linked to a somewhat different trend. The spread of 'academic capitalism' has strengthened a utilitarian view on higher education (Slaughter \& Rhoades, 2004). Feedback from students can be seen in this approach as an expression of consumer satisfaction and market information (Cardoso, 2012). This is qualitatively different from seeing students as key 'institutional actors', similarly to academic staff, whose legitimate role to participate in universities' affairs has been recognized for long. Cardoso and dos Santos (2011) claim that defining students as consumers may simplify and disempower their role, reducing their engagement to that of a passive informant about the present state of educaiton. The contribution of 'stakeholders' is conceptually different from 'consumer feedback', as will be elaborated below.

Most academic research on stakeholders in higher education is inspired by two theoretical streams. The most commonly used angle borrows from corporate governance literature and it assumes that universities as autonomous market players must learn to 'manage' their various stakeholders in order to succeed in their environment (e.g. Benneworth and Jongbloed (2010)). The stakeholder model by Mitchell, Agle, and Wood (1997) is effectively applied on universities, suggesting that a response to stakeholders' claims depends on stakeholders' power, and on urgency and legitimacy of their claims. Which stakeholders' claims are legitimate depends strongly on political norms and an institutional framework (Benneworth \& Jongbloed, 2010). 
A second angle is similar in its foundation but it raises from an organizational approach to a broader governance approach: it redefines government as an (external) stakeholder for universities. Boer, Enders, and Schimank (2007), relying on Olsen (1988) present 'stakeholder guidance' as one governance model in higher education, next to top-down state regulation, academic self-governance and others. Instead of being a provider or commander, the state articulates its wishes and interests through other means appropriate for influencing (semi-) autonomous universities, such as financial incentives, persuasion, etc. Universities have also other stakeholders besides the state, and the state is at the same time a complex actor that incorporates the interests of other stakeholders, such as the general public, students and employers (Jongbloed, Enders, \& Salerno, 2008). The state can also delegate some of its responsibilities to other stakeholders or representatives by asking them to serve at university boards, evaluation committees, and oversight agencies, for example.

The origins of the current trend towards stakeholder engagement can be drawn to a set of ideas captured in the 'better regulation' agenda and in 'collaborative' and 'participatory' approaches to governance. While the first angle above focuses on universities as strategic actors and the second angle redefines the relationship between universities and the state, this third angle focuses on the policy-making process. It builds on the idea that stakeholder involvement in designing and implementing regulation, in any policy sector, can make a significant contribution to accountability, legitimacy, and/or effectiveness of the regulation. Stakeholders contribute to this process with their unique expertise, experiences and expectations. As this framework provides the rationale for active stakeholder involvement currently in Europe and elsewhere, we build on this angle to understand the role of stakeholder engagement in this paper.

\section{Stakeholders and 'collaborative governance'}

'Stakeholder engagement' as a key principle for good policy-making and regulation is spreading rapidly. The principle has also strong organizational proponents, such as the European Commission and OECD through their 'better regulation' program (European Commission, 2015; OECD, 2012). The idea of stakeholder engagement is rooted in the transition from 'government' to 'governance', characteristic to the public sector reform of the 1990s and 2000s in many countries (Kooiman, 2003). The wave of deregulation, delegation, and decentralization in the public sector has led to a different view on the centrality of state power (Aucoin \& Heintzman, 2000). Furthermore, it is increasingly clear that many policy problems are interlinked, crossing sectorial borders, and requiring a multi-level and a multiactor response. This brings afore the concept of horizontal governance (Kickert 2001) where relationships are based more on co-ordinance than sub-ordinance, more on negotiation than command, and more on symmetrical communication and self-regulation (Michels \& Meijer, 2008). Greater reliance on diverse, also non-governmental actors leads to the idea that consulting and engaging stakeholders is an important element in successful governance.

Various streams of governance literature point to three main contributions that stakeholder engagement can make: contribution to effectiveness, to legitimacy and to appropriateness of a 
regulation or policy. A prevalent argument for stakeholder engagement builds on the idea that stakeholders have unique expertise in the sector. As policy fields get increasingly complex and presume collaboration between multiple actors, consulting stakeholders in shaping policies is important in order to detect potential bottle-necks in the system and thereby reach an effective regulation. Moreover, engaging a broad range of stakeholders can reduce the risk that regulation serves a particular interest group rather than the public in general (Ayres \& Braithwaite, 1992).

A second contribution of stakeholder engagement relates to the notion of 'accountability'. Introduction of semi-autonomous regulatory agencies, also in higher education quality assurance (Beerkens, 2015a), aimed to strengthen the role of expertise and to separate policy making from policy implementation. On the other hand, the 'agencification' trend brings afore some concerns about accountability and legitimacy. Agencies enjoy significant discretion in shaping procedures and policies but they are distanced from the political control and thereby from democratic will. Involving different stakeholders in agencies' supervisory boards, for example, is an attempt to strengthen accountability and legitimacy within the system. Studies show that societal stakeholders in supervisory boards rarely see themselves as representing the 'political principal' though, but they see their role as monitoring the discretion of agencies, contributing their expertise, and representing the unique perspective of the specific stakeholder group (Schillemans, 2008; Yesilkagit \& van Thiel, 2012). Stakeholders can thus contribute to other aspects of accountability, such as opening up a feedback mechanism to a broader audience and allow openness and reflexivity in political and administrative systems that might otherwise be primarily inward-looking (Bovens, Schillemans, \& Hart, 2008).

Thirdly, stakeholder engagement can be valuable not only for its outcome but also as a platform for shaping views through a communicative process. According to this idea, communication between stakeholders increases mutual understanding between actors. Such a process may increase the likelihood of a stable agreement and compliance, but it may also contribute positively to participants' sense of justice, fairness, and perceived legitimacy of the institutions involved (Blomgren Bingham, 2010). This perspective envisions the engagement process itself differently - it is built on the idea of communicative rationality, as opposed to strategic, functional or instrumental rationality of different interest groups (Blomgren Bingham, 2010).

Empirical literature over stakeholder engagement in various policy sectors identifies many successful cases, but it also suggests that the effects vary across policy sectors and issue domains. Stakeholder engagement is more likely to make a positive difference when it addresses issues characterized by multitude of societal actors and conflicting policy objectives, vague and incomplete problem definitions, and need for specialized knowledge (Edelenbos \& Klijn, 2006; Sørensen \& Torfing, 2009). Higher education is perhaps not a highly controversial and antagonistic policy field, but a vague problem definition, competing goals and different interests can be observed within this sector. 
Different perspectives on stakeholder engagement lead thus to a somewhat different vision about the nature and the objective of such an engagement. Its purpose can be either instrumental or normative; it may be either a tightly organized process through formal institutions and procedures, or encouraging bottom-up contributions in a loose approach. Moreover, stakeholders may be seen primarily as organized interest groups, citizens in general, or as any constellation between the two extremes. All of the approaches, however, assume that stakeholders hold systematically different views and these differences need to be incorporated in the policy-making process. In this paper we wish to test empirically the assumption that stakeholders indeed differ substantially in their views about quality assurance.

\section{Study design and data}

In order to map potential differences in stakeholders' views on quality assurance, we rely on focus group interviews among main stakeholder groups in Estonia. In this section we will first offer some background information on the Estonian context, and thereafter we discuss the sample and data analysis.

\section{The Estonian context}

The study is conducted in Estonia, a small binary higher education system with seven academic universities (one of which is private), and seventeen universities of applied sciences. Public universities are to a large extent publicly funded, with only a very small part of the budget covered by tuition fees. Quality assurance is organized The Estonian Quality Agency for Higher and Vocational Education (EKKA), founded in 2009 to replace the Accreditation Center established twelve years earlier. EKKA conducts two types of assessments: institutional accreditations and regular assessments of study programs (i.e. 'program group assessments'). Although EKKA is financed by the government, it is autonomous in developing its own procedures and guidelines as well as in its accreditation and assessment decisions. From the very beginning, EKKA has included different stakeholders in its activities, for example by including stakeholders in its assessment council that makes final accreditation and assessment decisions as well as in committees that develop requirements and criteria for a specific assessment.

\section{Sample}

Interviews were held among most commonly identified stakeholder groups. Two interviews were conducted with representatives of the state, including representatives from five ministries and leaders of local governments (a mayor and a county governor). Three interviews were conducted with entrepreneurs and top executives of public and private companies. Two interviews were carried out among high school students from four schools in different parts of the country, and two interviews among students from five universities. One interview was conducted with rectors and two interviews with teaching staff from five institutions. Among the interviews with students, academic staff and rectors, both academic universities and universities of applied sciences were represented. Altogether, 12 interviews were held with 68 people in total (Table 1). 
After a selection round, potential participants received an invitation via e-mail to participate. Approximately $60 \%$ of the persons agreed to participate. In the case of rejections the time and place did not suite, and in such cases employers and state representatives suggested a replacement.

\begin{tabular}{lll} 
Table 1. Focus groups & & \\
\hline Stakeholders & $\begin{array}{l}\text { Number of } \\
\text { groups }\end{array}$ & $\begin{array}{l}\text { Number of } \\
\text { participants }\end{array}$ \\
\hline Rectors & 1 & 9 \\
Academic staff & 2 & 13 \\
State officials & 2 & 9 \\
Employers & 3 & 16 \\
University students & 2 & 10 \\
High school students & 2 & 11 \\
TOTAL & 12 & 68 \\
\hline
\end{tabular}

\section{Interview design}

Focus groups are well-suited to study attitudes and opinions because they allow respondents to express their views in their own words, without being steered or constrained by a structured questionnaire, for example. The group process, furthermore, allows group participants to explain and clarify their views, and it informs researchers about how people think about an issue, not only what they think (Morgan \& Kreuger, 1993). The advantage of an unstructured format was confirmed by two pilot interviews. In one pilot interview, the participants received a list of possible aims of quality assurance and they were asked to choose five goals they see as most relevant, add goals if necessary, and then discuss their views with the group. The other pilot interview posed an open question about the aims of quality assurance, without any suggestions. The second option provided a broader range and richer answers and it was therefore the format for final interviews.

To enhance the reliability of the data and minimize the effects of an interviewer bias, two (or three) interviews were conducted with each stakeholder group, and by two different interviewers. Exception to this is the group of university rectors where only one interview was possible. Interviews lasted about one hour, except the interviews with high school students that lasted about 30 minutes.

Following recommendations for a successful focus group interview, the number of questions was limited to two: (a) "What is a good university?" and (b) "What should the aim of quality assurance in higher education be?" In case the discussion remained very limited, one additional interview question was posed: "Should external quality assurance take into account the context of an institution?" This paper discusses only the aims of the quality assurance.

Out of the twelve interviews, eight were audiotaped. In the other four cases either participants did not agree with recording or the surrounding environment was too noisy (e.g. a group of high school students was interviewed during a student fair). In these cases all key ideas were written down by the interviewer, and in the end the interviewer presented her notes to the participants and encouraged them to correct her or add more points. All recorded interviews were transcribed. 


\section{Operationalization and data analysis}

To systematize stakeholders' responses, we first extracted a list of potential aims of quality assurance from existing literature. A well-known categorization contrasts quality enhancement and accountability as two objectives of quality assurance (e.g. Dan $\varnothing$ and Stensaker (2007), and more recently transparency has been added to this list. For the purpose of this paper, we have extracted a more detailed list of possible aims as indicated in some key sources in this field (Brennan \& Shah, 2000; Harvey \& Newton, 2004; Schwartz \& Westerheijden, 2004). The exercise led to thirteen aims:

- to ensure accountability for the use of public funds;

- to steer the division of labor within the higher education sector;

- to improve the quality of higher education provision;

- to inform students and employers;

- to stimulate competitiveness within and between institutions;

- to undertake a quality check on new institutions;

- to assign institutional status as a response to increased diversity within higher education;

- to change the governance of universities;

- to encourage internationalization;

- to stimulate mobility of students;

- to make international comparisons;

- to ensure compliance with government or external agency requirements;

- to control the growth of private providers.

The list was adjusted and adapted during the process of data analysis. In the end, ten possible aims remained in the list that were grouped in four clusters for a better overview: information for external partners, internal development, control of standards and operations, and information for steering and policy-making (See Table 2 in the next section for the complete list.)

\section{Data analysis}

Interview transcripts were analyzed for any statements that addressed the purpose of the quality assurance or expectations to a quality assurance system. When possible, the identified statement was linked to one of the aims in the predefined list; otherwise a new category was created. For data analysis, 'summative content analysis' was used, which means counting and comparing (mostly) pre-specified arguments, or so-called 'nodes' (Hsieh \& Shannon, 2005). After this we analyzed how many times each node had been mentioned independently.

Counting nodes has some obvious weaknesses. It may bias against straightforward arguments that are so clear that participants have no reason to return to the arguments again later in the discussion, while more ambiguous arguments may get repeated with an attempt to clarify the argument further. Furthermore, classification of the arguments was in several instances challenging since several aims can entangle in one statement. Nevertheless, we consider the quantitative analysis as an informative indication of prevalent themes in each interview, and we add qualitative insights and illustrations in the form of quotes in order to enrich the analysis. 


\section{Results}

The interviews about possible aims for quality assurance brought up a variety of answers. According to quantitative counts (Table 2), aims that could be classified as 'controlling standards and operations' were most frequently discussed - 30 times across the 12 interviews, and mentioned by all stakeholder groups. This was followed by aims related to distributing 'information to external stakeholders' ( 23 nodes), most frequently mentioned by external stakeholders themselves (employers, perspective students, state representatives), but also by academic staff. Internal development was also frequently discussed (18 nodes), but primarily among internal stakeholders, that is by rectors and teachers. Finally, quality assurance as a tool to steer higher education landscape was less frequently mentioned (12 nodes) but it is a recognizable concern among state representatives and also employers.

While the counts give a good overview about the themes that received more or less attention by different stakeholder groups they also hide much of the nuance. We therefore summarize the key points that emerged in the interview for each stakeholder group in qualitative terms.

\section{Employers}

Employers emphasize the control function of quality assurance. The system has to make sure that education is up to the standard and that universities do what they are expected to do. Therefore employers are rather unanimously against the idea that quality assurance system should consider the specific characteristics of a university in the evaluation and adjust standards accordingly. This purpose is, however, closely linked to steering the higher education system. The assessment should also help to organize the higher education landscape, to avoid unnecessary duplication between universities and diffusing resources across too many institutions:

[The aim is to...] "objectively ensure that education is of high quality. That there wouldn't be too many universities, and that they were of quality, this should be the goal."

Besides the control function, employers also want to see that quality assurance offers information to external parties - students, parents, employers, society broadly - about quality of the university. Most importantly, the information should signal that it is a respectable institution, and to a lesser extent the information should offer some comparison and benchmarking between institutions:

"The results of external evaluation should reach the society .... Both prospective and enrolled students should know that they have a guarantee. ... It should send a clear message to society what goes well in the institution and what has been improved or is being improved."

Labor market relevance is a clearly visible theme in the answers of employers': 
"Quality assurance should give information about the graduate - who is the graduate and how ready he or she is. This is the most interesting piece of information for employers."

Employers expectedly link quality assurance with labor market needs, both at the program level and across programs. They wish to see that quality assurance considers what are actual needs and expectations to a graduate in a specific field and then assess the correspondence to the needs; and they expect quality assurance to coordinate that universities prepare graduates in the fields that are demanded in the labor market.

Interestingly, employers bring up the issue of leadership several times. The purpose of quality assurance is not only to control the quality of education, but also to assess that a university has a vision, ambition and knows where it is heading. In these answers employers seem to see the state as a "shareholder" who needs to oversee the management and its strategic vision:

"Critically important is the issue of leadership, the issue of organization, like is there a vision and development plan?"

"One of the aims could be to conceptualize the meaning of study fields, to think through, materialize, and monitor the mission, vision and development of the university. Whether the university itself has thought it through."

\section{University rectors}

Unlike employers, university rectors focus primarily on the formative function of the quality assurance. According to rectors, quality assurance should have a primary role in helping the organization, i.e. offer feedback from peers and contribute to improvement in education. Rectors are also sensitive about the uniqueness of each institution and understanding the context for a fair assessment:

"People at universities look forward to having a positive expert: a supportive, guiding assessment."

... not that some experts come [for a visitation] and say 'Why is it here not so as at our place in Barcelona?', for example.

"The end result [of quality assurance] should be a clear discussion about the source of the problems, what could be done better, so that institutions could indeed start improving their work". Not that you just generate more papers to show that you have completed the task."

The importance of assessing strategic aims and whether they are met is recognized also by rectors:

"... whether a university meets its expectations. The quality of leadership is [reflected in] its strategic plan - is it well done and feasible. Assessment should be then based on what is in the plan." 
Lastly, rectors see that evaluation results should reach the political decision makers, and particularly that good results should be also reflected in ministerial decision making, e.g. offer some guarantees about the future of the institution or a program.

... and once you have done it [i.e. accreditation] then the result is not only for the university but also for the Ministry to consider .... And once you have completed the full process, you have also some guarantee [for the future from the Ministry].

\section{Academic staff}

Similarly to rectors, academic staff also values greatly quality assurance for internal development and seems to value the reflection that a good assessment procedure encourages:

[The main aim of quality assurance is.... " "...supporting internal development of a higher education institution."

"Perhaps self-evaluation [as part of the external quality assurance system] is the most important aspect in the system."

Similarly to rectors, academic staff also sees that problems identified in the quality assurance process should be considered in ministerial decisions about how to make the system better and how to facilitate improvement. Unlike rectors, though, academic staff mentions that quality assurance should give information to external partners, and also comparative information to universities themselves.

"To some extent it is a necessary comparison object, with foreign universities as well, but it should remain in a reasonable limit."

Quality assurance as checking and controlling standards was discussed much in one interview but skipped in the other.

\section{Government representatives}

Government representatives perhaps expectedly focus somewhat more on quality assurance as an input for policy decisions. The process should help organize higher education landscape, decide where resources should flow, and steer what programs should be offered in which institutions.

[The aim is to encourage ....] "...specialization, not as a goal of itself but to ensure that high quality resources concentrate. Internationally competitive professors - if they are distributed between three different schools in the same field then it is less beneficial than if they work together in one place; they talk to each other and as a result they create more positive influence."

Similarly to employers, also government officials emphasize the need to focus on a long-term vision of the university:

"Somehow, this assessment could also provide an answer to whether it is a forwardlooking school. Whether it has the vision and the capability of implementing this vision." 
"... accreditation should find out whether a university is sustainable."

Government representatives also focus strongly on quality assurance as giving a guarantee to external partners (particularly to students) about the credibility of the institution. Internal development, however, does not come up much during the discussion.

\section{Current and prospective students}

Both university students and prospective students are somewhat narrower in their answers. Students define the purpose of quality assurance particularly through the quality of the graduates. Students want to make sure that universities keep up with time and that their education stays labor-market relevant in a quickly changing environment. They see that quality assurance is primarily a check on whether universities do what they are supposed to do.

[The purpose of quality assurance is to check] "whether a university offers education that it has promised to offer and whether its education is up to a standard".

If some problem comes up, if society changes, does the school respond then? That it is not doing something that does not fit any more [in the new environment].

If the country needs [....] engineers, whether graduates from the engineering program at the university $[X]$ can also work in practice as engineers.

In one interview with students, participants mention trust and credibility as the most important aim of quality assurance. In the other interview, students discuss the importance of competition between institutions as a positive outcome of quality assurance.

Prospective students expectedly focus on the informational role of quality assurance, to inform which universities are up to standard and to allow a comparison with other universities. Labor market relevance of the degree is very important among prospective students.

[To check that] "... when students graduate, that they can work in the field they study; that their skills and knowledge are sufficiently high.

How well they can transfer the specialization or how high is the quality of their specialization. [...] which school is the best in teaching the field.

Both student groups are modest about quality assurance for internal development (although mentioned once) and for government steering.

\section{Comparison between groups}

Comparing groups to each other, we see some expected differences. Most clearly, internal stakeholders - rectors and teachers - see the importance of quality assurance as a tool to facilitate improvement. In these discussions, a good quality assurance process is primarily supportive and constructive. Furthermore, they see that evaluation results should also reach the ministry, either to offer some certainty and rewards for good results, or to inform the ministry about the needs and weaknesses within the system that require addressing. External 
stakeholders - employers, prospective students, state representatives - expect that quality assurance provides information. They expect information about the credibility of an institution and to a lesser extent comparative information to help select partners or a study program. Also academic staff values the aspect of comparison, but not only for external stakeholders but also for institutions themselves. Also expectedly, prospective students in particular emphasize the role of information about programs.

The control function of quality assurance is most consistently present among all stakeholder groups. The emphasis, however, varies slightly. Both current and prospective students are most concerned about the overall quality of studies, and current students particularly about labor market relevance of their studies. Also employers share concerns about the overall level of studies, while rectors focus more on the strategic vision of universities. Interestingly, all groups, with the exception of students, see that quality assurance should be linked to looking at the university more broadly, to assess its vision and objectives for the future. 
Table 2. Aims of external quality assurance mentioned during the interview

\begin{tabular}{|c|c|c|c|c|c|c|c|}
\hline & $\begin{array}{l}\text { Empl } \\
\text { oyers }\end{array}$ & $\begin{array}{l}\text { State } \\
\text { repr. }\end{array}$ & $\begin{array}{c}\text { Rect } \\
\text { ors }\end{array}$ & $\begin{array}{l}\text { Teache } \\
\text { rs }\end{array}$ & $\begin{array}{l}\text { Stud } \\
\text { ents }\end{array}$ & $\begin{array}{l}\text { Prosp. } \\
\text { studen } \\
\text { ts }\end{array}$ & $\begin{array}{l}\text { Total } \\
\text { nodes }\end{array}$ \\
\hline 1 Externally oriented information & 3 & 2 & $\mathbf{0}$ & 2,5 & 0,5 & 2 & 23 \\
\hline $\begin{array}{l}\text { 1a Information to compare institutions (locally and } \\
\text { internationally) }\end{array}$ & $1 *$ & 0,5 & & $1,5^{*}$ & & $1^{*}$ & \\
\hline $\begin{array}{l}\text { 1b Assign institutional status (as a response to } \\
\text { increased diversity within HE) }\end{array}$ & $1 *$ & 0 & & 0,5 & & 0 & \\
\hline $\begin{array}{l}\text { 1c Inform stakeholders about the credibility of an } \\
\text { institution }\end{array}$ & $1 *$ & 1,5 & & 0,5 & 0,5 & $1^{*}$ & \\
\hline 2 Internal development & $\mathbf{0 , 3}$ & 1,0 & 6,0 & 4,0 & 0,5 & $\mathbf{0}$ & 18 \\
\hline 2a Improve the quality of higher education provision & 0 & 0,5 & 5 & 2,5 & 0,5 & & \\
\hline $\begin{array}{l}2 \mathrm{~b} \text { Feedback on long-term goals and vision of the } \\
\text { institution, discussions btw state and university about } \\
\text { future direction and needs }\end{array}$ & 0,3 & 0,5 & 1 & 1,5 & & & \\
\hline 3 Control standards and operations & 2,4 & 3,5 & 3 & 2 & 2,5 & 2 & 30 \\
\hline 3a To assure relevance of qualifications & 0,7 & 0,5 & & 1 & $1,5^{*}$ & 0,5 & \\
\hline 3bTo assure compliance with validated standards & $1 *$ & 1,5 & & 0,5 & $1,5^{*}$ & $1,5^{*}$ & \\
\hline $3 \mathrm{cTo}$ assess the quality of leadership & 0,7 & 1,5 & 3 & 0,5 & & & \\
\hline 4 Inform steering (policy-decisions) & 1,4 & 2,5 & $\mathbf{0}$ & 1,0 & 1 & $\mathbf{0}$ & 12 \\
\hline $\begin{array}{l}\text { 4a To optimize resources/higher education landscape } \\
\text { (e.g. avoid duplications) }\end{array}$ & 0,7 & $2 *$ & & 1 & 0,5 & & \\
\hline $\begin{array}{l}4 \mathrm{~b} \text { To assess the societal usefulness of publicly funded } \\
\text { activities }\end{array}$ & 0,7 & 0,5 & & 0 & & & \\
\hline 4c Encourage competition between institutions & & & & & 0,5 & & \\
\hline
\end{tabular}

Note: The scores present average 'nodes' per stakeholder group interview, i.e. the number of times a specific aim (or a cluster of aims) was mentioned divided by the number of interviews with the group. A star means that the aim was mentioned in every interview with the respective stakeholder group. Sum in the last column captures the total count of all nodes in the respective category. 


\section{Conclusion}

New governance principles expect active stakeholder engagement in all phases of policy making. Quality assurance is one area where stakeholder input is strongly encouraged. The expected purpose of engaging stakeholders is to make a policy more effective through wider expertise, commitment, and mutual understanding, but also through legitimacy and accountability that such an engagement may generate. All this assumes that stakeholders have different views about the nature and purpose of quality assurance.

The results of this empirical study show that stakeholders indeed have somewhat different views about the purpose of quality assurance. While all stakeholder groups seem to agree that quality assurance should offer some guarantee that education offered by an institution meets expected standards, a core difference is between quality assurance for improvement and for transparency. While internal stakeholders - university leaders and teachers - emphasize the importance of feedback and internal development, employers and students see the value of quality assurance in making information available to stakeholders and to society more broadly. All groups, with the exception of students, see that the quality assurance process could be an input for government steering more broadly.

The conclusions in this study are based on data from one specific setting, Estonia. It appears from the interviews that stakeholders' view is much influenced by what they perceive as the main problem with the higher education system. In the Estonian context, concerns that surface in the interviews relate to questionable standards in private universities, excessive duplication of study programs, and doubts about the competitiveness of the Estonian higher education on the world scale. While these concerns may be specific to the Estonian setting, interviews refer also to experiences that are characteristic to stakeholder groups. Stakeholders' responses can be linked to their specific role in the system - such as employing graduates, choosing a university, or steering public funds. Stakeholders also differ in their expertise about the daily operations of the higher education sector and the current quality assurance system, which colors their answers. These differences are likely to be shared across countries.

What does the diversity of views suggest for a quality assurance system? Incorporating different aims in a quality assurance may make the system more comprehensive and responsive to societal needs. It is, however, questionable whether all the aims are compatible with each other. Studies on 'policy mixes' suggest that some policy instruments may form 'toxic' combinations because different tools assume a different motivational structure of those addressed by the tools (Gunningham \& Sinclair, 1999). While transparency tools tend to be relatively compatible with most other types of instruments, mixing quality control and quality enhancement may be more difficult. Transparency tools may also conflict with the enhancement purpose if collected information is not perceived as comprehensive or valid to represent true quality. Effective policy mixes in higher education may need some further analysis. Successful regulation of complex policy areas often requires co-existence of diverse regulatory principles though, it requires 'layering' and 'nesting' (Ostrom, 1990). It is therefore important to think how instruments of different nature could be separated, also in 
terms of organizations responsible for their implementation. Some of the concerns articulated by stakeholders are or can be addressed by other policy instruments, by regular performance agreements or universities' oversight bodies, for example.

On the other hand, stakeholders' views do not seem to be drastically different. There is a shared idea in quality assurance as a tool for controlling quality and standards in universities. It is also a widely shared view that quality assurance should contribute to steering higher education system. It is hard to point to any principle disagreement among stakeholders; rather stakeholders respond from their unique experience and expertise. Differences between stakeholders should not therefore be taken at the face value. Communication between different stakeholders is likely to smoothen some of these differences. As discussed before, stakeholder engagement serves also the function of increasing mutual understanding, through a communicative process.

Some diversity in views is however essential for effective stakeholder engagement. Stakeholders tend to be reluctant to cooperate in case the final outcome is seen as already predictable, or if the issue is not seen as a priority, or if they see the issue as something that government should just solve on its own. Increasing demand for stakeholder input in various policy areas puts also high pressure on key stakeholder groups, such as employers' and students' associations, for example. A diversity of views among stakeholders and some conflict around quality assurance in higher education are preconditions for stakeholder engagement to have a real impact.

An attempt to map stakeholders' expectations in Estonia led the Estonian quality agency to define clearly what the aims and the main target group for each of their reviews are. The agency decided that the main target group of program level assessments is the university itself, and their primary focus is therefore on recommendations for educational quality. The purpose of an institutional accreditation, however, is more broadly defined, including not only strategic management and culture of quality, but also informing stakeholders about educational outcomes, and enhance the reliability and competitiveness of Estonian higher education.

What could active stakeholder engagement contribute to shaping a quality assurance system, in the light of the results of this study? Engagement could broaden an overall view on what a quality assurance system should cover. It might help avoid an inward-looking, processoriented, technical approach to quality assurance. Sharing different perspectives and expertise could contribute to common understanding of what the system should offer, and increase support and legitimacy to the system. Stakeholder engagement can thus enrich and improve a system, but with a danger of contributing to the ambiguity of its core purpose. A systematic study of stakeholders' expectations in Estonia contributed to clarifying but also broadening the approach to quality assurance in the Estonian quality assurance agency.

Stakeholder engagement has much potential to enrich the discussion, but it is not likely to answer the question of what exactly is the core function of a public quality assurance system. Stakeholder engagement, as clearly demonstrated in other policy sectors, never replaces the 
need for a vision and leadership, but it can support leadership and it can contribute to a broadly shared vision. 
References

Alves, H., Mainardes, E. W., \& Raposo, M. (2010). A relationship approach to higher education institution stakeholder management. Tertiary Education and Management, 16(3), 159-181.

Aucoin, P., \& Heintzman, R. (2000). The dialectics of accountability for performance in public management reform. International Review of Administrative Sciences, 66(1), 45-55.

Ayres, I., \& Braithwaite, J. (1992). Responsive regulation : transcending the deregulation debate. New York: Oxford University Press.

Bach, T., Dragojevic, D., Findlay, P., Hering, S., Lauri, L., Lynch, O., ... Udam, M. (2014). Transparency of European Higher Education Through Public Quality Assurance Reports (EQArep): Final report of the project. Occassional report 21. . Brussels: ENQA.

Beerkens, M. (2015a). Agencification problems in higher education quality assurance. In E. Reale \& E. Primeri (Eds.), The Transformation of University Institutional and Organizational Boundaries (pp. 43-62). Rotterdam: Sense.

Beerkens, M. (2015b). Quality assurance in the political context: in the midst of different expectations and conflicting goals. Quality in Higher Education, 21(3), 231-250.

Benneworth, P., \& Jongbloed, B. (2010). Who matters to universities? A stakeholder perspective on humanities, arts and social sciences valorisation. Higher Education, 59(5), 567-588.

Blomgren Bingham, L. (2010). Collaborative Governance. In M. Bevir (Ed.), The SAGE Handbook of Governance (pp. 386-401). Los Angeles: Sage.

Boer, H. d., Enders, J., \& Schimank, U. (2007). On the Way towards New Public Management? The Governance of University Systems in England, the Netherlands, Austria, and Germany. In D. Jansen (Ed.), New Forms of Governance in Research Organizations: Disciplinary Approaches, Interfaces and Integration (pp. 137-152).

Bovens, M., Schillemans, T., \& Hart, P. T. (2008). Does public accountability work? An assessment tool. Public Administration, 86(1), 225-242.

Brennan, J., \& Shah, T. (2000). Managing quality in higher education : an international perspective on institutional assessment and change. Buckingham England; Philadelphia, PA: Organisation for Economic Co-operation and Development, Society for Research into Higher Education \& Open University Press.

Burrows, J. (1999). Going Beyond Labels: A Framework for Profiling Institutional Stakeholders. Contemporary Education, 70(4), 5.

Cardoso, S. (2012). Students' perceptions of quality assessment. In B. Stensaker, J. Välimaa, \& C. Sarrico (Eds.), Managing Reform in Universities: The Dynamics of Culture, Identity and Organisational Change (pp. 135-155). Basingstoke,UK: Palgrave Macmillan.

Danø, T., \& Stensaker, B. (2007). Still Balancing Improvement and Accountability? Developments in External Quality Assurance in the Nordic Countries 1996-2006. Quality in Higher Education, 13(1), 81-93.

Diamond, R. M. (2008). Designing and assessing courses and curricula : a practical guide (3rd ed.). San Francisco: Jossey-Bass.

Edelenbos, J., \& Klijn, E.-H. (2006). Managing Stakeholder Involvement in Decision Making: A Comparative Analysis of Six Interactive Processes in the Netherlands. Journal of Public Administration Research and Theory, 16(3), 417-446.

European Commission. (2015). Better regulation guidelines, Commission staff working document. $\operatorname{SWD}(2015) 111$.

Freeman, R. E. (1984). Strategic management: a stakeholder approach. Boston: Pitman.

Gunningham, N., \& Sinclair, D. (1999). Regulatory Pluralism: Designing Policy Mixes for Environmental Protection. Law \& Policy, 21(49-76).

Harvey, L., \& Newton, J. (2004). Transforming quality evaluation. Quality in Higher Education, 10(2), 149-165.

Hopbach, A. (2014). Recent trends in quality assurance? Observations from the agencies' perspectives (Eds) , pp. 216-230 (Basingstoke, Palgrave). In M. J. Rosa \& A. Amaral (Eds.), 
Quality Assurance in Higher Education: Contemporary Debates (pp. 216-230). Basingstoke: Palgrave.

Hsieh, H. F., \& Shannon, S. E. (2005). Three approaches to qualitative content analysis. Qualitative Health Research, 15(9), 1277-1288.

Jongbloed, B., Enders, J., \& Salerno, C. (2008). Higher education and its communities: Interconnections, interdependencies and a research agenda. Higher Education, 56(3), 303324.

Kooiman, J. (2003). Governing as governance. London ; Thousand Oaks, Calif.: SAGE.

Michels, A., \& Meijer, A. (2008). Safeguarding public accountability in horizontal government. Public Management Review, 10(2), 165-173.

Mitchell, R. K., Agle, B. R., \& Wood, D. J. (1997). Toward a theory of stakeholder identification and salience: Defining the principle of who and what really counts. Academy of Management Review, 22(4), 853-886.

Morgan, D. L., \& Kreuger, R. A. (1993). When to use focus groups and why. In D. L. Morgan (Ed.), Successful focus groups: Advancing the state of the art (pp. 3-19). London: Sage.

OECD. (2002). Responding to student expectations Paris: OECD.

OECD. (2012). Recommendation of the Council on Regulatory Policy and Governance.

Olsen, J. P. (1988). Administrative reform and theories of organization. In C. Campbell \& B. G. Peters (Eds.), Organizing governance, governing organizations (pp. 233-254). Pittsburgh: University of Pittsburgh Press.

Ostrom, E. (1990). Governing the Commons: The Evolution of Institutions for Collective Action. Cambridge, UK: Cambridge University Press.

QQI, Q. a. Q. I. (2014). Review of Reviews: Report of the Independent Review Team: QQI.

Santiago, P., Tremblay, K., Basri, E., \& Arnal, E. (2008). Tertiary Education for Knowledge Society: Volume 1 (Governance, Funding, Quality). Paris: OECD.

Schillemans, T. (2008). Accountability in the Shadow of Hierarchy: The Horizontal Accountability of Agencies. Public Organization Review, 8(2), 175-194.

Schwartz, S., \& Westerheijden, D. F. (2004). Accreditation in the Framework of Evaluation Activities: A Comparative Study in the European Higher Education Area. Dordrecht: Spinger.

Slaughter, S., \& Rhoades, G. (2004). Academic capitalism and the new economy : markets, state, and higher education. Baltimore: Johns Hopkins University Press.

Smeby, J.-C., \& Stensaker, B. (1999). National quality assessment systems in the Nordic countries: developing a balance between external and internal needs? Higher Education Policy, 12(1), 314.

Sørensen, E. V. A., \& Torfing, J. (2009). MAKING GOVERNANCE NETWORKS EFFECTIVE AND DEMOCRATIC THROUGH METAGOVERNANCE. Public Administration, 87(2), 234-258.

Stensaker, B., \& Vabø, A. (2013). Re-inventing Shared Governance: Implications for Organisational Culture and Institutional Leadership. Higher Education Quarterly, 67(3), 256-274.

Watson, D. (2012). Who runs our universities? Perspectives: Policy and Practice in Higher Education, 16(2), 41-45.

Yesilkagit, K., \& van Thiel, S. (2012). Autonomous Agencies and Perceptions of Stakeholder Influence in Parliamentary Democracies. Journal of Public Administration Research Theory, 22(1), 101119. 